University of Wollongong

Research Online

Faculty of Engineering and Information

Faculty of Engineering and Information

Sciences - Papers: Part A

Sciences

January 2015

Deterministic methodologies for the quantification of voltage unbalance propagation in radial and interconnected networks

Jayatunga Vitharanage Upuli Priyadarshani Jayatunga

jvupj453@uowmail.edu.au

Sarath Perera

University of Wollongong, sarath@uow.edu.au

Philip Ciufo

University of Wollongong, ciufo@uow.edu.au

Ashish P. Agalgaonkar

University of Wollongong, ashish@uow.edu.au

Follow this and additional works at: https://ro.uow.edu.au/eispapers

Research Online is the open access institutional repository for the University of Wollongong. For further information contact the UOW Library: research-pubs@uow.edu.au 


\title{
Deterministic methodologies for the quantification of voltage unbalance propagation in radial and interconnected networks
}

\begin{abstract}
Voltage unbalance propagation is an important aspect in relation to the voltage unbalance management process which aims to maintain acceptable voltage unbalance levels in the power system. The IEC Technical Report IEC/TR 61000-3-13:2008 incorporates the effects of voltage unbalance propagation in the voltage unbalance emission allocation methodology by introducing the voltage unbalance transfer coefficient, in order to evaluate the influence made by background voltage unbalance at the point of evaluation. However, no comprehensive approaches exist in the literature to evaluate these coefficients and the IEC work follows some approximations, which are deduced based on simulations and practical measurements. Recent work completed on voltage unbalance emission assessment at the postconnection stage of unbalanced installations allows separation of the voltage unbalance emission contribution made by upstream/surrounding unbalance sources as a constituent component of the resultant voltage unbalance emission level at the point of evaluation. These new methodologies implicitly deal with the important aspects of voltage unbalance propagation and allow the quantification of coefficients associated with voltage unbalance propagation, which is the main thrust of this study. The theoretical work completed by considering different types of loads in radial and interconnected networks is supplemented by the simulation results.
\end{abstract}

\section{Keywords}

deterministic, propagation, voltage, methodologies, quantification, radial, interconnected, unbalance, networks

\section{Publication Details}

U. Jayatunga, S. Perera, P. Ciufo \& A. P. Agalgaonkar, "Deterministic methodologies for the quantification of voltage unbalance propagation in radial and interconnected networks," IET Generation, Transmission \& Distribution,, vol. 9, (11) pp. 1069-1076, 2015. 


\title{
Deterministic Methodologies for the Quantification of Voltage Unbalance Propagation in Radial and Interconnected Networks
}

\author{
Authors \\ Upuli Jayatunga (jvupj453@uowmail.edu.au), Sarath Perera (sarath@uow.edu.au), Phil Ciufo \\ (ppc@uow.edu.au) and Ashish P. Agalgaonkar (ashish@uow.edu.au) \\ All authors are affiliated with the Australian Power Quality and Reliability Centre, School of \\ Electrical, Computer and Telecommunications Engineering, University of Wollongong, NSW 2522, \\ Australia
}

Please address all correspondence to Dr Phil Ciufo.

NOTICE: this is the authors' version of a work that was accepted for publication in IET Generation, Transmission and Distribution. Changes resulting from the publishing process, such as peer review, editing, corrections, structural formatting, and other quality control mechanisms may not be reflected in this document. Changes may have been made to this work since it was submitted for publication. A definitive version was subsequently published in IET Generation, Transmission and Distribution, DOI: $10.1049 /$ iet-gtd.2014.0661

\begin{abstract}
Voltage unbalance propagation is an important aspect in relation to the voltage unbalance management process which aims to maintain acceptable voltage unbalance levels in the power system. The IEC Technical Report IEC/TR 61000-3-13:2008 incorporates the effects of voltage unbalance propagation in the voltage unbalance emission allocation methodology by introducing the voltage unbalance transfer coefficient in order to evaluate the influence made by background voltage unbalance at the point of evaluation. However, no comprehensive approaches exist in the literature to evaluate these coefficients and the IEC work follows some approximations which are deduced based on simulations and practical measurements. Recent work completed on voltage unbalance emission assessment at the post-connection stage of unbalanced installations, allows separation of the voltage unbalance emission contribution made by upstream/surrounding unbalance sources as a constituent component of the resultant voltage unbalance emission level at the point of evaluation. These new methodologies implicitly deal with the important aspects of voltage unbalance propagation and allow the quantification of coefficients associated with voltage unbalance propagation, which is the main thrust of this paper.
\end{abstract}


The theoretical work completed by considering different types of loads in radial and interconnected networks is supplemented by simulation results.

\section{Keywords}

power quality, voltage unbalance, voltage unbalance propagation, voltage unbalance transfer coefficient, voltage unbalance influence coefficient voltage unbalance emission assessment, network asymmetry, load asymmetry

\section{Introduction}

Voltage unbalance (VU) in electric power systems is primarily caused by asymmetrical distribution of loads and untransposed transmission lines. Although the connection of an unbalanced installation changes the existing unbalance level at the point of evaluation (POE), that installation is not solely responsible for the total VU emission level resulting at the POE as network inherent asymmetries partly contribute to the net emission. Further, the resultant voltage unbalance emission level at a POE is influenced by the background/surrounding unbalance which is transferred through the network [1]. Thus, quantification of level of voltage unbalance which is propagated to a certain location is important in determining the net VU emission level in relation to VU management.

The VU propagation studies presented in [2], [3] and [4] investigate the influence made by the propagated unbalance from upstream or surrounding locations in terms of the total VU factor at the POE instead of the exact portion that is transferred to the POE. Further, the probabilistic estimation of voltage unbalance in distribution networks that is presented in [5] does not consider simultaneously existing unbalance sources. Instead, a probabilistic methodology is established in order to evaluate the VU caused due to unbalanced loads only. Some relevant discussion on VU propagation is presented using state estimation techniques in [6] in order to evaluate the level, location and effects of VU in distribution networks. The IEC VU emission allocation methodology [1] determines the exact level of VU that propagates from a specific location of the network to the POE which influences the total VU emission capability at the POE by accommodating a fraction of upstream/surrounding through VU transfer and influence coefficients. However, there are no systematic approaches for the evaluation of these two factors under practical system operating conditions [7]. Instead, the IEC Technical Report [1] recommends that system operators determine those factors through simulations and measurements. This rudimentary approach given in [1] has been shown to have anomalies based on recent studies on VU management [8] [9].

VU management essentially requires the total VU absorption capacity of the power system to 
be distributed among all sources of unbalance, including customer installations, to maintain relevant compatibility levels [10]. The IEC Technical Report IEC/TR 61000-3-13:2008 [1] provides guiding principles on the allocation of individual emission limits to unbalanced installations. In addition, the compliance assessment at the post-connection stage of installations against the allocated limits is another requirement for which no proper methodologies currently exist in the IEC context. However, recent work completed on VU emission assessment [11] [12], which provides further contributions to the development of IEC/TR 61000-3-13:2008 in relation to compliance assessment at the post-connection stage of unbalanced installations establishes generalised approaches to classify major VU emission contributors and evaluate their level of contributions on the resultant VU factor at the POE as decoupled quantities. Accordingly, the influence made by background voltage unbalance (upstream or surrounding unbalance) on the total VU emission at the POE is identified as a primary emission contributor and the individual emission contribution is estimated employing upstream/surrounding VU factors. The deterministic methodologies presented in [11] and [12], covering radial and interconnected networks respectively, evaluate these individual VU emission contributions utilising pre/post-connection voltage/current measurements and known network parameters.

The outcomes of the proposed deterministic methodologies detailed in [11] and [12] have paved paths for new investigations to be carried out in relation to the VU propagation in a systematic manner. Hence, the primary objective of the work presented in this paper is to develop generalised methodologies for the quantification of VU propagation in radial and interconnected networks utilising the approaches used for VU emission assessment.

This paper is organised as follows: Section 2 gives a critical discussion on the present IEC approach on evaluating VU propagation coefficients (VU transfer and influence coefficients), identifying their shortcomings and limitations. Generalised outcomes of VU emission assessment techniques presented in [11] and [12] are summarised in Section 3, establishing the foundation for the work given in Section 4, which covers comprehensive methodologies for evaluating VU propagation coefficients. This work is supplemented by employing simulation results presented in Section 5. Conclusions are given in Section 6.

\section{Evaluation of VU Propagation Coefficients: the IEC Approach}

\subsection{Transfer Coefficient}

In a radial network, the level of VU that is transferred to the downstream busbar from upstream is expressed as a portion of the planning level of the upstream busbar which is scaled down using the 
transfer coefficient. Accordingly, the VU transfer coefficient represents a fraction of upstream VU that is transferred to the considered downstream busbar as given in (1).

$$
T_{\mathrm{us}-i}=\frac{u_{i}}{u_{\mathrm{us}}}
$$

where $T_{\mathrm{us}-i}$ is the VU transfer coefficient from upstream to $i^{\text {th }}$ downstream system; $u_{i}$ and $u_{\mathrm{us}}$ are VU factors in the $i^{\text {th }}$ downstream and upstream systems respectively.

The reader should note that the concept of the VU transfer coefficient has been established in a similar manner to that of the flicker transfer coefficient [13], which is defined as the fraction of upstream flicker that is transferred to the downstream system as given by $\frac{P_{s t, A}}{P_{s t, B}}$ where $P_{s t, A}$ and $P_{s t, B}$ represent flicker levels at downstream system (busbar $A$ ) and upstream system (busbar $B$ ) respectively. Application of these definitions to evaluate electromagnetic disturbance emission transfers is questionable since the definitions rely on the fact that the new disturbing load (which is to be provided with an emission allocation limit) that is yet to be connected, does not influence the disturbance transfer. As an example, in the case of flicker analysis, total flicker level at the downstream busbar is influenced by the upstream flicker source and the characteristics of the downstream load. That is, $P_{s t, B}$ incorporates the contributions made by $P_{s t, A}$ as well as the downstream load (in an additive or subtractive manner).

In the case of VU emission, network asymmetries influence the resultant VU emission level at the downstream busbar in addition to the contributions made by load asymmetry, load type and the upstream VU that propagates to the downstream system. That is, when measurements are carried out, $u_{i}$ in (1) consists of not only the influence made by $u_{u s}$, but also includes the contribution made by the load and line asymmetries as well. In essence, a transfer coefficient which is established in a pre-connection stage is subjected to variations as a new installation is connected and hence needs re-evaluation.

In addition, the VU emission allocation methodology [1] does not specify any systematic approach to evaluate these transfer coefficients under practical system operating conditions. The IEC report [1] recommends that system operators determine these factors through either simulations or measurements. As a conservative guide, the transfer coefficient can be approximated to unity whereas it can take values less than unity in the case where three-phase induction motors exist in the downstream systems. Accordingly, the VU transfer coefficient from MV (upstream) to LV (downstream) ( $T_{\mathrm{uML}}$ ) 
can be evaluated approximately using (2) [1];

$$
T_{\mathrm{uML}}=\frac{1}{1+k_{m} \frac{k_{s}-1}{k_{s c+1}}}
$$

where $k_{m}$ is the ratio of rated motor power in MVA to total load MVA supplied by the LV system; $k_{s}$ is the ratio between positive and negative sequence impedances of the motor load supplied by the LV system; $k_{s c}$ is the ratio of LV short circuit level to total load in MVA supplied by the LV system.

\subsection{Influence Coefficient}

The influence coefficient $\left(k_{i-x}\right)$ gives a measure of VU propagation in interconnected networks. The coefficient $k_{i-x}$, related to busbars $i$ and $x$, is defined as the VU which arises at busbar $x$ when 1 pu of negative sequence voltage is applied at busbar $i$. This coefficient is employed in the HV/EHV emission allocation procedure in determining the total available apparent power as seen by the busbar under observation to account for the contributions made by the neighbouring busbars in interconnected networks. This definition does not account for the effects of simultaneously existing sources of unbalance (caused by the interconnected nature) at the busbar $x$ (i.e. multiple busbars connected to the busbar under assessment through different lines). Further, similar to the case of the transfer coefficient, VU emission at busbar $x$ arises as a result of the influence made only by the unbalance applied at busbar $i$. Otherwise, the VU at busbar $x$ is affected by other load and line asymmetries.

Further studies in relation to VU propagation, [8] [9], which have addressed the deficiencies of the IEC approach have demonstrated that the transfer coefficient has a dependency on the type of load (e.g. whether it is a passive load or an induction motor load) connected at the downstream busbar. Accordingly, a typical range for the transfer coefficient was proposed as $1.1 \geq T_{M V-L V} \geq 0.6$. Further, with respect to interconnected networks, influence coefficients were found to be approximately equal to unity in the case of passive loads and were shown to be considerably smaller than unity when induction motor loads are connected at the busbar $x$, [14] [15]. However, the methodologies presented in [8], [14] and [9] are quite complex and are based on several approximations. Further, they follow the IEC approach on VU propagation so that network characteristics are utilised through the use of short circuit capacity at the POE which does not reveal the actual network configuration or topology in a precise manner. 


\section{Post-connection VU Emission Assessment in Radial and Intercon- nected Power Systems}

Systematic approaches can be developed to quantify the VU propagation by further analysing the deterministic methodologies developed for decomposition of post-connection VU emission at the POE. VU emission assessment techniques given in [11] and [12] present a generalised approach for identifying different sources of unbalance at the POE while separating the customer and network responsibility on VU emission. Accordingly, the resultant post-connection VU emission measurement at the POE was decomposed into three factors by identifying major VU emission contributors as follows:

- load asymmetry (local load connected at the busbar under assessment, i.e. POE);

- line asymmetries (untransposed line/s connected to the busbar under assessment); and

- background unbalance (upstream or surrounding busbars that are connected to the busbar under assessment, represented using unbalanced voltage sources).

Hence, the constituent components of the resultant post-connection VU emission at the POE were established as asymmetrical load contribution, asymmetrical line contribution and upstream/surrounding source contribution which are given in (3) in terms of the complex VU factors ${ }^{1}$ for radial networks and in (4) for interconnected networks.

$$
V U F_{P O E}=V U F_{P O E}^{\mathrm{load}}+V U F_{P O E}^{\mathrm{line}}+V U F_{P O E}^{\text {source }}
$$

Referring to a radial network, $V U F_{P O E}$ is the resultant (total) VU factor at the POE; $V U F_{P O E}^{\text {load }}$ is the VU emission contribution made by load asymmetry; $V U F_{P O E}^{\text {line }}$ is the VU emission contribution made by line asymmetry and $V U F_{P O E}^{\text {source }}$ is the $\mathrm{VU}$ emission contribution made by upstream source.

$$
V U F_{k}=V U F_{k}^{\text {load }}+V U F_{k}^{\text {line }}+V U F_{k}^{\text {d_source }}
$$

Referring to an interconnected network, $V U F_{k}$ is the resultant VU factor at busbar $k$ (i.e. busbar under assessment); $V U F_{k}^{\text {load }}$ is the $\mathrm{VU}$ emission contribution made by the $k^{\text {th }}$ bus load at busbar $k ; V U F_{k}^{\text {line }}$ is the $\mathrm{VU}$ emission contribution made by all lines connected to busbar $k$ which can be expanded as $\sum_{i \neq k}^{n} V U F_{k-i}^{\text {line }}\left(V U F_{k-i}^{\text {line }}\right.$ is the contribution made by the line $k-i$, the line between busbars $k$ and $i$ on busbar $k$ ) and $V U F_{k}^{\text {source }}$ is the $\mathrm{VU}$ emission contribution made by surrounding busbars (local busbars) which are connected to busbar $k$ via lines $\left(\sum_{i \neq k}^{n} V U F_{\mathrm{k}-\mathrm{i}}^{\mathrm{d} \text { source }}\right)$.

\footnotetext{
${ }^{1} \mathrm{VU}$ factor (VUF) is defined as the ratio of negative sequence voltage to positive sequence voltage.
} 
Mathematical formulations presented in [11] and [12] evaluate these three components as decoupled contributions in such a way that they reflect own asymmetries through the decoupled formulation. These individual contributions are given in Tables 1 and 2 for radial and interconnected networks respectively for different load types considered ${ }^{2}$. The reader should note that the mathematical symbols used to represent constituent components of resultant VU emission at the POE in this paper have been subjected to slight modifications compared to the original formulations presented in [11] and [12].

\begin{tabular}{|c|c|c|}
\hline $\begin{array}{l}\text { Row } \\
\text { iden- } \\
\text { tifier }\end{array}$ & $\begin{array}{l}\text { Individual contrib- } \\
\text { utor }\end{array}$ & Mathematical expression for the contribution made \\
\hline \multicolumn{3}{|c|}{ Passive loads } \\
\hline 1 & $\begin{array}{l}\text { Load asymmetry } \\
V U F_{P O E}^{\text {load }}\end{array}$ & $\left(V U F_{P O E}-C U F\right) \frac{V_{\text {reg-line }}}{\left(1+V_{\text {reg-line }}\right)}$ \\
\hline 2 & $\begin{array}{l}\text { Line asymmetry } \\
V U F_{P O E}^{\text {line }}\end{array}$ & $-\frac{Z_{21, t}}{Z_{11, t}} \frac{V_{\text {reg-line }}}{\left(1+V_{\text {reg-line }}\right)}$ \\
\hline 3 & $\begin{array}{l}\text { Source asymmetry } \\
V U F_{P O E}^{\text {source }}\end{array}$ & $V U F_{\text {source }}$ \\
\hline \multicolumn{3}{|c|}{ Induction motor loads } \\
\hline 4 & $\begin{array}{l}\text { Line asymmetry } \\
V U F_{P O E}^{\text {line }}\end{array}$ & $-\left(\frac{Z_{2, m}}{Z_{1, m}}\right)\left(\frac{Z_{21, t}}{Z_{22, t}+Z_{2, m}}\right)$ \\
\hline 5 & $\begin{array}{l}\text { Source asymmetry } \\
V U F_{P O E}^{\text {source }}\end{array}$ & $\left(\frac{Z_{2, m}}{Z_{1, m}}\right)\left(\frac{Z_{1, m}+Z_{11, t}}{Z_{2, m}+Z_{22, t}}\right) V U F_{\text {source }}$ \\
\hline \multicolumn{3}{|c|}{ Mixed loads } \\
\hline 6 & $\begin{array}{l}\text { Load asymmetry } \\
V U F_{P O E}^{\text {load }}\end{array}$ & $\left(V U F_{P O E}-C U F_{\text {Pload }}\right)\left(\frac{Z_{1, m} Z_{2, m}\left(V_{\text {reg-line }}-\frac{Z_{22, t}}{Z_{1, m}}\right)}{Z_{1, m} Z_{2, m}\left(1+V_{\text {reg-line }}\right)+Z_{22, t}\left(Z_{1, m}-Z_{2, m}\right)}\right)$ \\
\hline 7 & $\begin{array}{l}\text { Line asymmetry } \\
V U F_{P O E}^{\text {line }}\end{array}$ & $-\frac{Z_{21, t}}{Z_{11, t}}\left(\frac{Z_{1, m} Z_{2, m} V_{\text {reg-line }}}{Z_{1, m} Z_{2, m}\left(1+V_{\text {reg-line }}\right)+Z_{22, t}\left(Z_{1, m}-Z_{2, m}\right)}\right)$ \\
\hline 8 & $\begin{array}{l}\text { Source asymmetry } \\
V U F_{P O E}^{\text {source }}\end{array}$ & $\left(\frac{Z_{1, m} Z_{2, m}\left(1+V_{\text {reg-line }}\right)}{Z_{1, m} Z_{2, m}\left(1+V_{\text {reg-line }}\right)+Z_{22, t}\left(Z_{1, m}-Z_{2, m}\right)}\right) V U F_{\text {source }}$ \\
\hline
\end{tabular}

Table 1: VU emission assessment outcomes: radial networks [11]

Referring to Table 1:

$C U F_{\text {Pload }}$ - current unbalance factor of the passive load;

$V U F_{\text {source }}$ - VUF of the upstream busbar;

$Z_{x y, t}$ - sequence impedance of the transmission line. Terms $x$ and $y$ can be replaced with 1 and 2 which stand for positive and negative sequence respectively;

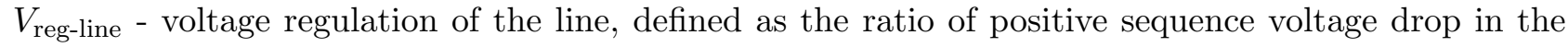
line to positive sequence voltage at the load; and

$Z_{x, \mathrm{~m}}$ - sequence impedance of the motor $(x=1$ or 2$)$.

\footnotetext{
${ }^{2}$ Mixed load behaviour in relation to interconnected networks is not included in the work due to the extreme complexity involved in the mathematical formulation.
} 


\begin{tabular}{|l|l|l|}
\hline $\begin{array}{l}\text { Row } \\
\text { iden- } \\
\text { tifier }\end{array}$ & $\begin{array}{l}\text { Individual contrib- } \\
\text { utor }\end{array}$ & Mathematical expression for the contribution made \\
\hline Passive loads & $\begin{array}{l}\text { Load asymmetry } \\
V U F_{k}^{\text {load }}\end{array}$ & $\sum_{i \neq k}^{n}\left(C U F_{k}-V U F_{k}\right) \frac{Y_{11: k i}}{Y_{22: k k}} V_{\text {drop-t }(k-i)}$ \\
\hline 1 & $\begin{array}{l}\text { Line asymmetry } \\
V U F_{k}^{\text {line }}\end{array}$ & $-\sum_{i \neq k}^{n} \frac{Y_{21: k i}}{Y_{22: k k}} V_{\text {drop-t }(k-i)}$ \\
\hline 3 & $\begin{array}{l}\text { Source asymmetry } \\
V U F_{k}^{\text {d_source }}\end{array}$ & $-\sum_{i \neq k}^{n} \frac{Y_{22: k i}}{Y_{22: k k}}\left(1+V_{\text {drop-t }(k-i)}\right) V U F_{i}$ \\
\hline Induction motor loads & $\begin{array}{l}\text { Line asymmetry } \\
V U F_{k}^{\text {line }}\end{array}$ & $\sum_{i \neq k}^{n} \frac{Y_{21: k i} V_{\text {drop-t }(k-i)}}{Y_{2: m}-Y_{22: k k}}$ \\
\hline 4 & $\begin{array}{l}\text { Source asymmetry } \\
V U F_{k}^{\text {d_source }}\end{array}$ & $\sum_{i \neq k}^{n} \frac{Y_{22: k i}\left(1+V_{\text {drop-t }(k-i)}\right)}{Y_{2: m}-Y_{22: k k}} V U F_{i}$ \\
\hline 5
\end{tabular}

Table 2: VU emission assessment outcomes: interconnected networks [12]

Referring to Table 2:

$C U F_{k}$ - current unbalance factor at $k^{t h}$ busbar;

$V U F_{k}$ - voltage unbalance factor at $k^{t h}$ busbar;

$Y_{x y: k i}$ - elements of nodal bus admittance matrix developed for the network in sequence domain. Terms $x$ and $y$ can be replaced with 1 and 2 which stand for positive and negative sequence respectively.

Terms $k$ and $i$ represent different busbars; and

$V_{\text {drop-t }(k-i)}$ - normalised voltage drop of line $k-i$ (normalised using bus $k$ voltage) defined as $\frac{U_{1, i}-U_{1, k}}{U_{1, k}}$ where $U_{1, x}$ is the positive sequence voltage of busbar $x$. In the analysis of the radial power system (in Table 1) this voltage drop was identified as voltage regulation because of the unidirectional power flow from source to load.

\section{Evaluation of VU Propagation Coefficients}

VU emission decomposition outcomes given in (3) and (4) for radial and interconnected networks respectively, separate the source (upstream/surrounding busbars) contribution $\left(3^{\text {rd }}, 5^{\text {th }}\right.$ and $8^{\text {th }}$ rows in Table 1 and $3^{\text {rd }}$ and $5^{\text {th }}$ rows in Table 2) which is the level of upstream/surrounding unbalance that is transfered to the POE as a fraction of the VU factor of upstream/local busbars ${ }^{3}$. That is, $V U F_{P O E}^{\text {source }}=k . V U F_{\text {source }}$ in the case of radial networks and $V U F_{k-i}^{\text {d_source }}=k . V U F_{i}$ for interconnected networks where $k$ is a complex scaling factor. Therefore, VU propagation coefficients can be evaluated using the scaling factor $(k)$ associated with source contributions based on the IEC definitions of VU

\footnotetext{
${ }^{3} \mathrm{VU}$ emission assessment methodology presented in [12] incorporates the term 'local busbars' to distinguish the surrounding busbars which are connected to busbar under assessment via transmission lines (i.e. local lines).
} 
transfer while considering simultaneously existing sources of unbalance at the POE.

In the case of radial networks, the VU propagation coefficient which represents the fraction of upstream unbalance that is transfered to downstream $\left(p c_{p o e-u s}\right)$ can be defined as a phasor quantity as given in (5);

$$
p c_{p o e-u s}=\frac{V U F_{P O E}^{\text {source }}}{V U F_{\text {source }}}
$$

where $V U F_{P O E}^{\text {source }}$ is the contribution made by the upstream busbar (source) to the POE and $V U F_{\text {source }}$ is the VU factor at the upstream busbar.

In the case of interconnected networks, the VU propagation coefficient with respect to busbar $k$ resulting from the influence made by busbar $i\left(p c_{k-i}\right)$ which represents a fraction of the VU emission at busbar $i$ that is transfered to busbar $k$ can be defined as follows:

$$
p c_{k-i}=\frac{V U F_{k-i}^{\mathrm{d} \_ \text {source }}}{V U F_{i}}
$$

where $V U F_{k-i}^{\text {d_source }}$ is the local busbar contribution made to busbar $k$ by busbar $i$ and $V U F_{i}$ is the resultant VU factor of the $i^{\text {th }}$ busbar.

Although the new definitions of VU propagation coefficients, (5) and (6), are established as phasor quantities, the following sections demonstrate that VU propagation coefficients are not sensitive to the phasor angle and they can be evaluated as scalar quantities in terms of known system parameters for different load types. Thus, the new quantification provides a path to overcome the limitations and shortcomings of the IEC approach in determining VU transfer and influence coefficients when applied to practical networks.

\subsection{Voltage Unbalance Emission Propagation in Radial Networks}

\subsubsection{Passive Loads}

In the case of passive loads connected at the POE, upstream VU is transfered to the downstream busbar (POE) without any attenuation (i.e. $V U F_{P O E}^{\text {source }}=V U F_{\text {source }}$ ). Thus, the VU propagation coefficient as a scalar quantity for passive loads $\left(P C_{p o e-u s}^{p l}\right)$ can be considered to be equal to unity as shown in (7). This outcome can be used to support the IEC approach where the MV-LV transfer coefficient is considered to be approximately equal to unity for radial networks extending from MV to LV.

$$
P C_{p o e-u s}^{p l}=\left|p c_{p o e-u s}^{p l}\right|=1
$$




\subsubsection{Three-phase Induction Motor Loads}

In the case of three-phase induction motor loads connected at the POE, the scaling factor associated with the upstream source contribution given by $\left(\frac{Z_{2, m}}{Z_{1, m}}\right)\left(\frac{Z_{1, m}+Z_{11, t}}{Z_{2, m}+Z_{22, t}}\right)$ which incorporates network and motor impedances, modifies the upstream source VU factor to represent the amount of VU that propagates to the downstream load busbar. The magnitude of this scaling factor was shown to be less than unity [11] and it merely acts as a scalar quantity for a given network and motor configuration, as the associated phase angle is very small (close to zero) for all scenarios considered. Hence, a generalised expression for the VU propagation coefficient can be established (considering only the absolute value) for three-phase induction motor loads in radial networks as given by (8).

$$
P C_{\text {poe-us }}^{\text {im }}=\left|p c_{\text {poe-us }}^{\text {im }}\right|=\left|\left(\frac{Z_{2, m}}{Z_{1, m}}\right)\left(\frac{Z_{1, m}+Z_{11, t}}{Z_{2, m}+Z_{22, t}}\right)\right|
$$

\subsubsection{Mixed Loads}

Similar to the cases of passive loads and induction motor loads, the scaling factor which modifies the VU of the upstream source $\left(8^{\text {th }}\right.$ row in Table 1$)$ represents the fraction of VU that transfers to the downstream busbar. Therefore, the VU propagation coefficient $P C_{p o e-u s}^{m l}$ can be established considering only the magnitude of the relevant scaling factor as given in (9).

$$
P C_{\text {poe-us }}^{m l}=\left|\left(\frac{Z_{1, m} Z_{2, m}\left(1+V_{\text {reg-line }}\right)}{Z_{1, m} Z_{2, m}\left(1+V_{\text {reg-line }}\right)+Z_{22, t}\left(Z_{1, m}-Z_{2, m}\right)}\right)\right|
$$

$P C_{\text {poe-us }}^{m l}$ is sensitive to the changes in the load composition as it is governed by the sequence impedances of the induction motor and the voltage regulation of the line, which is a measure of the line loading.

\subsection{Voltage Unbalance Propagation in Interconnected Networks}

\subsubsection{Passive Loads}

When passive loads are connected at the POE, each scaling factor associated with VU factors of local busbars $V U F_{i}$ (i.e. $-\frac{Y_{22: k i}}{Y_{22: k k}}\left(1+V_{\text {drop-t }(k-i)}\right)-5^{\text {th }}$ row of Table 2$)$ represents the fraction of VU that propagates from that particular busbar (busbar $i$ ) to the busbar under assessment (busbar $k$ ).

Similar to the case of radial networks, a generalised expression can be established to evaluate the VU propagation coefficient in relation to busbar $k$ by considering the influence made by busbar $i$ 
$\left(P C_{k-i}^{p l}\right)$ as given in $(10)$.

$$
P C_{k-i}^{p l}=\left|p c_{k-i}^{p l}\right|=\left|\frac{Y_{22: k i}}{Y_{22: k k}}\left(1+V_{\operatorname{drop}-\mathrm{t}(k-i)}\right)\right|
$$

In (10), $Y_{22: k i}$ is the negative sequence admittance of the line $k-i$ and $Y_{22: k k}$ is the sum of individual negative sequence admittances of all lines connected to busbar $k$ (i.e. $Y_{22: k k}=Y_{22: k 1}+Y_{22: k 2}+\ldots+$ $\left.Y_{22: k i}\right) . \quad V_{\text {drop-t }(k-i)}$ is the normalised positive sequence voltage drop of the line $k-i$. According to (10), $P C_{k-i}^{p l}$ is primarily governed by the ratio $\frac{Y_{22: k i}}{Y_{22: k k}}$ as $\left(1+V_{\text {drop-t }(k-i)}\right)$ has a limited variation in its magnitude (i.e. around $10 \%-15 \%$ ). Therefore, $P C_{k-i}^{p l}$ primarily depends on the network topology $\left(Y_{22: k k}\right)$ while there is a small influence made by the line loading level which is governed by the voltage regulation of the line. Further, VU propagation is not sensitive to the network asymmetry nor the load unbalance since $P C_{k-i}^{p l}$ is influenced by the negative sequence impedance/admittance of the line (noting that, for passive elements, negative sequence impedances are equal to positive sequence impedances), but not by the inherent asymmetries (i.e. $C U F$ nor $Z_{21, t}$ ).

The scaling factors associated with $V U F_{i}$ can be verified using the results obtained from the analysis of the IEEE 14 bus test system and the $66 \mathrm{kV}$ interconnected sub-transmission system as given in Section 5.2.

\subsection{Voltage Unbalance Propagation in Interconnected Networks}

\subsubsection{Three-phase Induction Motor Loads}

In the case of induction motor loads connected at the POE, the scaling factor associated with $V U F_{i}$ which evaluates the local busbar contribution quantifies the VU that propagates from busbar $i$ to busbar $k$ as given in (11). Similar to the case of passive loads, extensive simulation studies show that the VU propagation coefficients can be treated as scalar quantities $\left(P C_{k-i}^{i m}\right)$ by considering only the magnitude since the phase angles associated with $p c_{k-i}^{i m}$ can be approximated to zero.

$$
P C_{k-i}^{i m}=\left|p c_{k-i}^{i m}\right|=\left|\frac{Y_{22: k i}\left(1+V_{\mathrm{drop}-\mathrm{t}(k-i)}\right)}{Y_{2: m}-Y_{22: k k}}\right|
$$




\section{$5 \quad$ Verification of the Methodology}

\subsection{VU propagation in Radial networks}

\subsubsection{Three-phase Induction Motor Loads}

The following case study demonstrates the sensitivity of VU propagation coefficient $P C_{\text {poe-us }}^{i m}$ to different motor ratings and network characteristics.

The $12.47 \mathrm{kV}$ radial power system supplying a $2.3 \mathrm{kV}, 2250 \mathrm{hp}$ motor and a $2.3 \mathrm{kV}, 500 \mathrm{hp}$ motor ${ }^{4}$ (one motor is considered at a time) was modelled in DIgSILENT/PowerFactory simulation platform to study the VU propagation behaviour when supplied by untransposed lines ${ }^{5}$ of different lengths. The VU propagation coefficients evaluated using (8) for different cases, together with the resulting voltage regulation of the line are given in Table 3 and are graphically illustrated in Fig. 1.

\begin{tabular}{|c|c|c|c|c|c|c|}
\hline \multirow{3}{*}{$\begin{array}{l}\text { line } \\
\text { length } \\
\mathrm{km}\end{array}$} & \multicolumn{3}{|c|}{$2.3 \mathrm{kV}, 2250 \mathrm{hp}$ motor } & \multicolumn{3}{|c|}{$2.3 \mathrm{kV}, 500 \mathrm{hp}$ motor } \\
\hline & \multirow{2}{*}{$\begin{array}{l}\text { Voltage } \\
\text { regula- } \\
\text { tion } \\
V_{\text {reg-line }} \\
\%\end{array}$} & \multicolumn{2}{|c|}{$\begin{array}{l}\text { VU Propagation co- } \\
\text { efficient } p c_{\text {poe }}^{i m}\end{array}$} & \multirow{2}{*}{$\begin{array}{l}\text { Voltage } \\
\text { regula- } \\
\text { tion } \\
V_{\text {reg-line }} \\
\%\end{array}$} & \multicolumn{2}{|c|}{$\begin{array}{l}\text { VU Propagation co- } \\
\text { efficient } p c_{p o e}^{i m}\end{array}$} \\
\hline & & $\begin{array}{l}\text { Magnitude } \\
P C_{\text {poe }}^{\text {im }}\end{array}$ & $\begin{array}{l}\text { angle (in } \\
\text { deg) }\end{array}$ & & $\begin{array}{l}\text { Magnitude } \\
P C_{\text {poe }}^{\text {im }}\end{array}$ & $\begin{array}{ll}\text { angle } & \text { (in } \\
\text { deg) }\end{array}$ \\
\hline 1 & $2.6 \angle 180$ & 0.88 & 1.2 & $2.5 \angle 180$ & 0.91 & 0.4 \\
\hline 5 & $4.7 \angle 180$ & 0.81 & 4.1 & $3.0 \angle 180$ & 0.89 & 0.95 \\
\hline 10 & $5.3 \angle 180$ & 0.73 & 7.1 & $3.0 \angle 179$ & 0.87 & 1.6 \\
\hline 20 & $14.0 \angle 178$ & 0.62 & 12 & $4.5 \angle 179$ & 0.83 & 2.8 \\
\hline 25 & $18.0 \angle 178$ & 0.53 & 15 & $4.7 \angle 179$ & 0.81 & 3.2 \\
\hline
\end{tabular}

Table 3: VU propagation coefficients $\left(P C_{p o e-u s}^{i m}\right)$ for the radial network supplying 3-phase induction motor loads

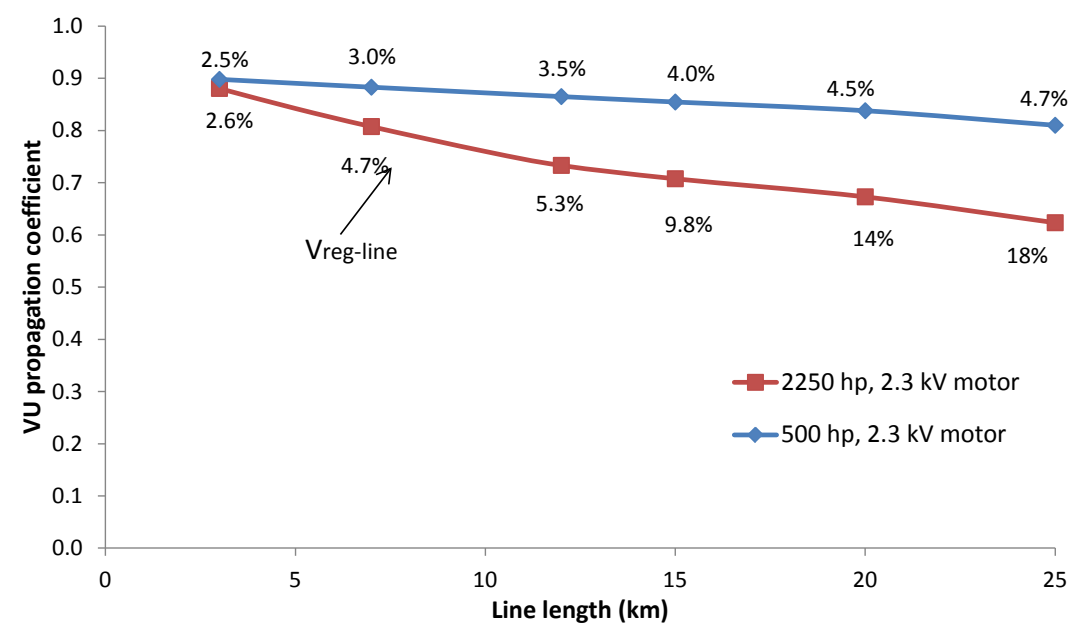

Figure 1: VU propagation coefficients $\left(P C_{p o e-u s}^{i m}\right)$ for different three-phase induction motor loads in a radial network

${ }^{4} 60 \mathrm{~Hz}, 4$ pole induction motor parameters are given in [16]

${ }^{5}$ Details of the line are given in Appendix A 
The following conclusions can be made based on the results presented in Table 3 and Fig. 1.

- As the phase angle associated with the propagation coefficient is nearly zero (columns 4 and 7 of Table 3), consideration of a scalar quantity is sufficient for $P C_{u s-p o e}^{i m}\left(=\left|p c_{u s-p o e}^{i m}\right|\right)$.

- As demonstrated in Fig. 1, longer lines (i.e. higher levels of $V_{\text {reg-line}}$ ) lead to smaller VU propagation coefficients.

- $P C_{p o e-u s}^{i m}$ is seen to be similar in magnitude for both motors when the same voltage regulation of the line $\left(V_{\text {reg-line }}\right)$ is maintained (when the $V_{\text {reg-line }}$ is $4.7 \%, P C_{\text {poe-us }}^{i m}$ is in the range of 0.80-0.81). Normally, pu impedances of induction motors which are derived based on their own rated values are approximately equal $\left(Z_{1: m 1}=Z_{1: m 2}\right.$ and $\left.Z_{2: m 1}=Z_{2: m 2}\right)$ irrespective of the power rating of the motor. Since pu impedance per unit length of the transmission line is constant for a specific line design, same voltage regulation can appear in both cases for different line lengths where nearly identical VU propagation factors arise as noted above.

\subsubsection{Mix of Passive and Induction Motor Loads}

The formulation given in (9) is compared with the IEC approach to determine the MV to LV transfer coefficients as given by (2). The following case study demonstrates the variation of VU propagation coefficient $P C_{\text {poe-us }}^{m l}$ evaluated for the radial network ${ }^{6}$ shown in Fig. 2 which supplies a 1.2 MVA mixed load $(2.3 \mathrm{kV}, 500 \mathrm{hp}$ three-phase induction motor loads and $2.3 \mathrm{kV}$ constant power loads) for different load compositions: (a) by applying (9), and (b) by the application of (2) (IEC approach). This network was modelled in DIgSILENT/PowerFactory simulation platform.

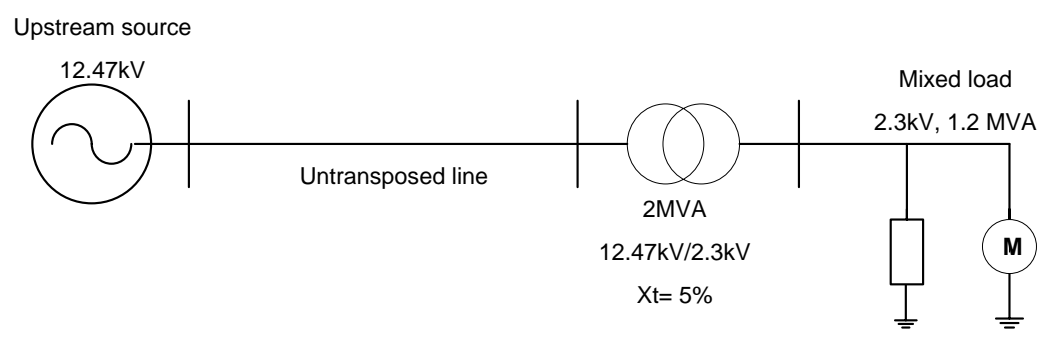

Figure 2: MV-LV radial network containing a mixed load

As shown in Fig. 3, when the load comprises only passive loads (i.e. $k_{m}=0$ ), the VU propagation coefficient is equal to unity as expected. That is, the total upstream VU emission is transfered to the POE with no attenuation. When the proportion of the motor load is increased in the mixed load, the transfer coefficient decreases as a result of the increment of VU attenuation provided by induction

\footnotetext{
${ }^{6}$ untransposed line details are given in Appendix A.
} 
motors. The maximum attenuation can be obtained when $k_{m}=1$ (i.e. total load is composed of threephase induction motors only). Further, it can be seen that the outcomes of the IEC approach for evaluating VU transfer coefficients are slightly conservative compared to the proposed approach when the mixed load has a higher proportion of induction motor loads.

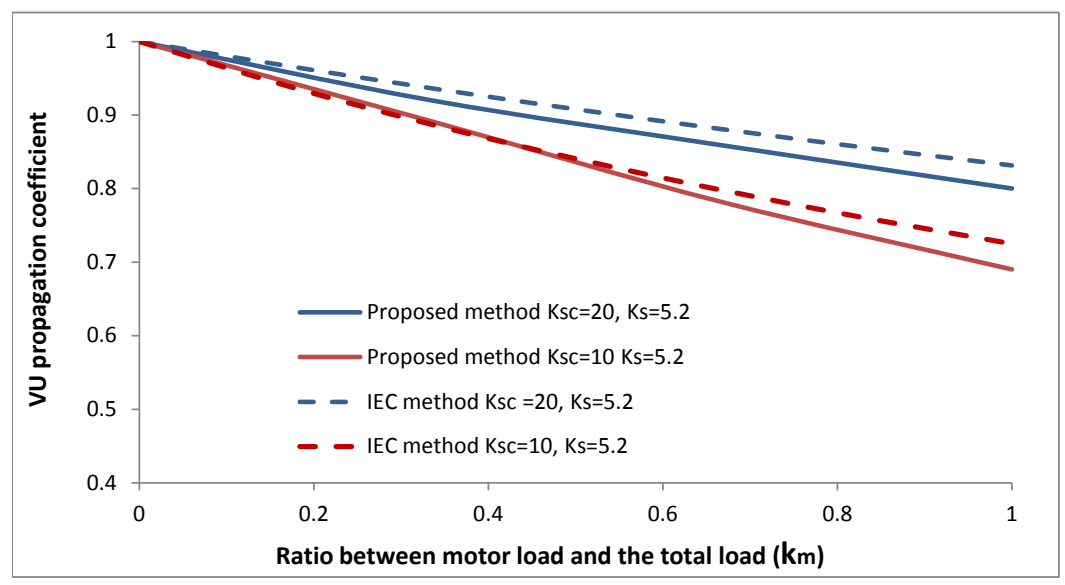

Figure 3: VU propagation coefficients evaluated for a radial network in the presence of a mixed load in comparison to the IEC approach given in (2)

\section{$5.2 \quad$ VU propagation in Interconnected Networks}

\subsubsection{Analysis of IEEE 14 Bus Test System}

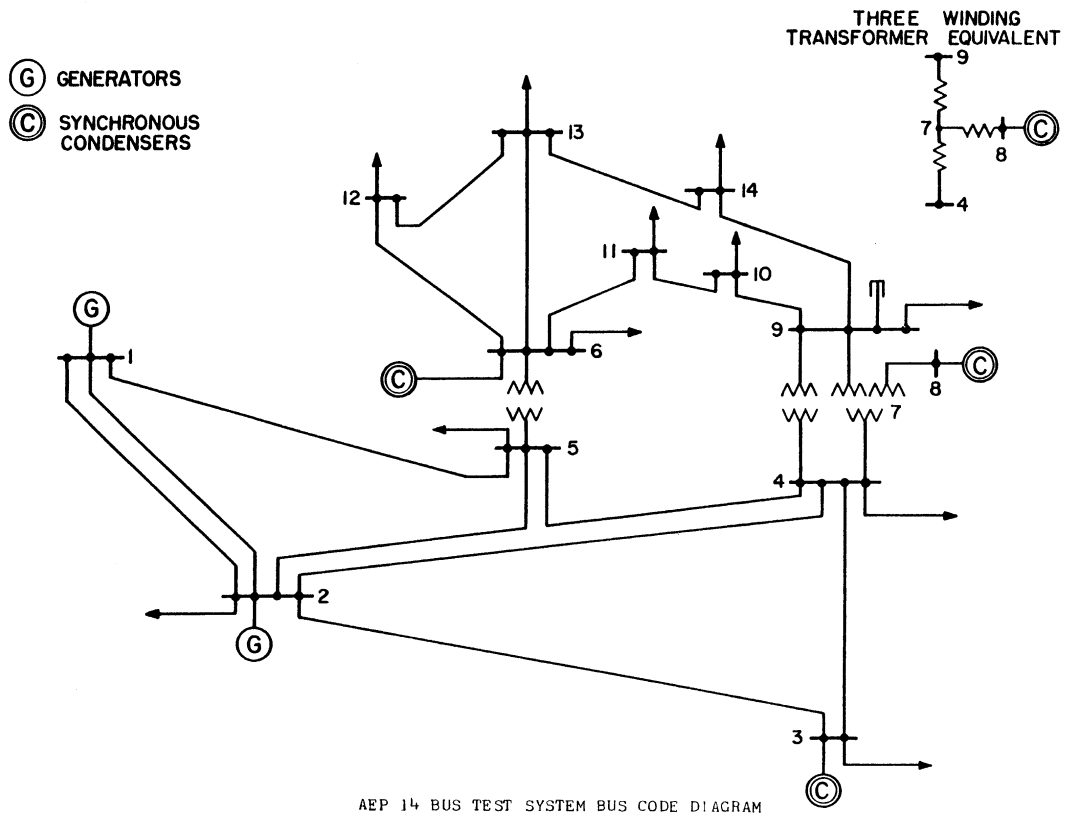

Figure 4: IEEE 14 bus test system

VU propagation coefficients are evaluated for the IEEE 14 bus test system shown in Fig. 4 using (10) and utilising the VU emission assessment outcomes discussed in [12] $\left(P C_{k-i}^{p l}=\left|\frac{V U F_{k-i}^{\mathrm{d} \text { source }}}{V U F_{i}}\right|\right)$ and 
are shown in Table 4. It is to be noted that the IEEE 14 bus test system contains voltage controlled busbars where negligible VU emission levels are assumed at busbars 1, 2, 3,6 and 8. Further, the 14 bus test system is assumed to supply three-phase balanced constant power loads since the propagation coefficients have been noted to be independent of both load and network asymmetries. The $60 \mathrm{~Hz}$, three-wire system data used are as per [9] and [17]. The IEEE 14-bus test system was simulated using the unbalanced load-flow program written in MATLAB.

\begin{tabular}{|l|l|l|l|}
\hline $\begin{array}{l}\text { Busbar under } \\
\text { assessment }\end{array}$ & $\begin{array}{l}\text { Local bus- } \\
\text { bar }\end{array}$ & $i$ & $\begin{array}{l}\text { VU Propagation coeffi- } \\
\text { cient } p c_{k-i}^{p l}\end{array}$ \\
\cline { 2 - 4 } & & $\begin{array}{l}\text { Magnitude } \\
P C_{k-i}^{p l}\end{array}$ & $\begin{array}{l}\text { angle (in de- } \\
\text { grees) }\end{array}$ \\
\hline 4 & 5 & 0.57 & 0.07 \\
\hline 4 & 7 & 0.13 & -0.30 \\
\hline 4 & 9 & 0.05 & -0.34 \\
\hline 5 & 4 & 0.62 & 0.0 \\
\hline 9 & 4 & 0.07 & -0.06 \\
\hline 9 & 7 & 0.37 & -0.12 \\
\hline 9 & 10 & 0.45 & 0.10 \\
\hline 9 & 14 & 0.13 & 0.09 \\
\hline 10 & 9 & 0.70 & 0.0 \\
\hline 10 & 11 & 0.31 & 0.0 \\
\hline 11 & 10 & 0.51 & 0.0 \\
\hline 12 & 13 & 0.49 & 0.0 \\
\hline 13 & 12 & 0.03 & 0.0 \\
\hline 13 & 14 & 0.91 & 0.0 \\
\hline 14 & 9 & 0.03 & 0.0 \\
\hline 14 & 13 & 0.97 & 0.0 \\
\hline
\end{tabular}

Table 4: VU propagation coefficients evaluated for the IEEE 14 bus test system

\subsubsection{Analysis of $66 \mathrm{kV}$ Interconnected Sub-Transmission Network}

VU behaviour of a practical, $66 \mathrm{kV}$ interconnected sub-transmission network shown in Fig. 5 was investigated in [18] using the proposed emission assessment methodology given in [12] in order to find out VU sources, their level of contributions and to facilitate ranking of emission sources. Based on the VU emission separation outcomes given in [18], VU propagation coefficients for the $66 \mathrm{kV}$ network are evaluated adopting the same approach as discussed in relation to IEEE 14 bus test system and the results are given in Table 5. Busbar S1 is considered to be the bulk supply point where the voltage unbalance has been measured to be negligible. This network was simulated using unbalanced load-flow program written in MATLAB. Following observations can be made in relation to VU propagation in interconnected networks with passive loads based on the results tabulated for the two test systems.

- Consideration of a scalar quantity for VU propagation coefficient can be justified by analysing column 4 of Tables. 4 and 5 as the phase angle associated with $p c_{k-i}^{p l}$ is close to zero. 


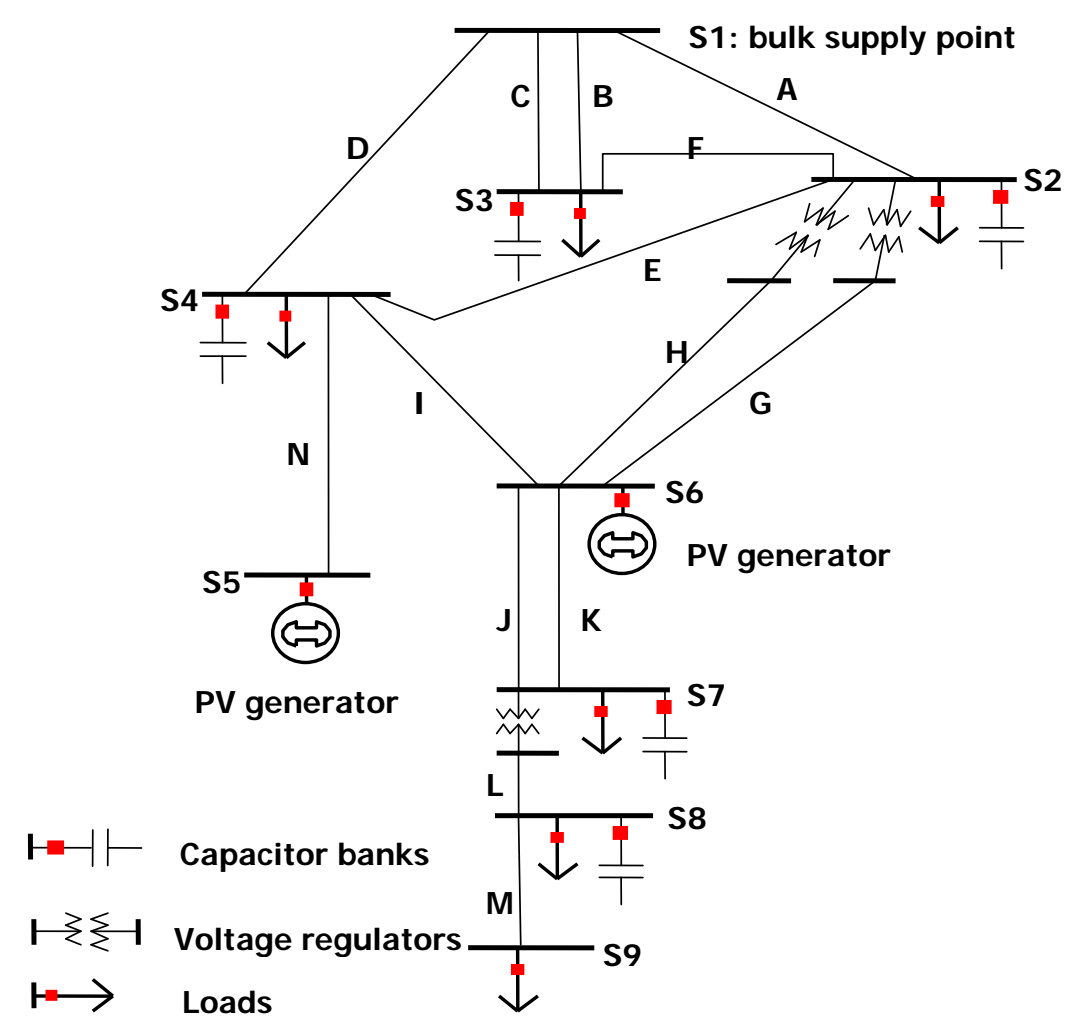

Figure 5: $66 \mathrm{kV}$ interconnected sub transmission network

\begin{tabular}{|l|l|l|l|}
\hline $\begin{array}{l}\text { Busbar under } \\
\text { assessment }\end{array}$ & $\begin{array}{l}\text { Local bus- } \\
\text { bar }\end{array}$ & $\begin{array}{l}\text { VU Propagation coeffi- } \\
\text { cient } p c_{k-i}^{p l}\end{array}$ \\
\cline { 3 - 4 } & & $\begin{array}{l}\text { Magnitude } \\
P C_{k-i}^{p l}\end{array}$ & $\begin{array}{l}\text { angle (in de- } \\
\text { grees) }\end{array}$ \\
\hline S2 & S6 & 0.78 & 0.23 \\
\hline S2 & S3 & 0.04 & 0.70 \\
\hline S2 & S4 & 0.08 & 0.58 \\
\hline S3 & S2 & 0.13 & 0.20 \\
\hline S4 & S5 & 0.37 & 0.03 \\
\hline S4 & S2 & 0.34 & 0.19 \\
\hline S4 & S6 & 0.17 & -0.29 \\
\hline S5 & S4 & 0.88 & -0.02 \\
\hline S6 & S2 & 0.90 & 0.03 \\
\hline S6 & S7 & 0.78 & -0.08 \\
\hline S6 & S4 & 0.11 & 0.03 \\
\hline S7 & S8 & 0.82 & 0.6 \\
\hline S7 & S6 & 0.28 & 0.20 \\
\hline S8 & S7 & 0.46 & 0.28 \\
\hline S8 & S9 & 0.59 & -0.18 \\
\hline S9 & S8 & 1.01 & 0.01 \\
\hline
\end{tabular}

Table 5: VU propagation coefficients evaluated for the $66 \mathrm{kV}$ interconnected sub-transmission network

- IEEE 14 bus test system can be regarded as a highly meshed network compared to the $66 \mathrm{kV}$ interconnected network. Referring to the values given Tables 4 and 5, VU propagation coefficients of highly meshed networks can be seen to be relatively small compared to those of networks with relatively less interconnections. This situation arises due to the fact that a VU propagation 
coefficient is primarily governed by the network topology where $Y_{22: k k}$ increases with the number of interconnections that the busbar $k$ has, thus resulting lower values for the ratio $\frac{Y_{22: k i}}{Y_{22: k k}}$.

- The VU propagation coefficient related to busbar $k$ due to busbar $i\left(P C_{k-i}^{p l}\right)$ and the reverse effect (i.e. $P C_{i-k}^{p l}$ - VU propagation coefficient at busbar $i$ due to busbar $k$ ) are not always equal to each other since $Y_{22: k k}$ is not identical for the two busbars as a result of different interconnections.

- The VU propagation coefficient can take values greater than unity for the most downstream busbar (S9 in the $66 \mathrm{kV}$ interconnected network) since $Y_{22: k i}=Y_{22: k k}$ and $\left|1+V_{\text {drop-t }(k-i)}\right|>1.0$.

The presence of power transformers in the power system has been represented in the assessment formulation by considering three decoupled sequence impedances in series with the line impedance. Therefore the impact made by power transformers on VU propagation is considered in this methodology, since the elements of nodal Y bus matrix developed for a given network includes the transformer impedances/admittances.

\section{Conclusions}

This paper has established systematic methodologies to quantify VU propagation in radial and interconnected networks based on the recently completed VU emission assessment work. The influence made by upstream/surrounding busbar unbalance on the resultant VU emission at the POE was identified as a constituent component of the total VUF at the POE and quantified as a fraction of upstream/surrounding busbar VUF. Thus, generalised expressions which contain known network and load parameters were deduced to evaluate VU propagation coefficients considering different types of loads connected at the POE. Further, it was demonstrated that VU propagation coefficients can be treated as scalar quantities.

The deterministic methodologies developed for radial networks provide a sound basis for the determination of VU transfer coefficient in relation to the IEC VU emission allocation process. The deterministic approaches used to establish the VU propagation coefficients for interconnected networks can be used for evaluation of the influence coefficients in HV and EHV networks.

- For radial networks, in the case of passive loads connected at the POE, VU propagation coefficient $\left(P C_{p o e-u s}^{p l}\right)$ is equal to unity whereas VU propagation coefficient $\left(P C_{k-i}^{p l}\right)$ primarily depends on the network topology in interconnected networks.

- VU propagation coefficients $\left(P C_{p o e-u s}^{i m}\right.$ or $\left.P C_{k-i}^{i m}\right)$ evaluated at busbars with induction motor 
loads is always less than unity since three-phase induction motors tend to attenuate pre-existing VU levels at the connected busbar regardless of the network characteristics.

- VU propagation coefficients evaluated at busbars with mixed loads were shown to vary depending on the load composition.

Following the guidance given in the IEC Technical Report, VU propagation coefficients required for the VU emission allocation process (i.e. considering unbalanced installations which are yet to be connected to the system) can be precisely evaluated using the proposed formulation by undertaking proper simulation studies of the post-connection system which establish the required post-connection data (voltage regulation of the line) for the proposed methodology.

\section{A Details of $12.47 \mathrm{kV}$ Untransposed Line}

- Tower construction details: $1.143 \mathrm{~m}$ flat and horizontal

- Conductor data:

- Geometric mean radius $=7.7724 \mathrm{~mm}$

- AC resistance $=0.19014 \Omega / \mathrm{km}$

- Earth resistivity $=100 \Omega . \mathrm{m}$

- Calculated line impedance matrix $\left(\left[Z_{a b c}\right] / \mathrm{km}\right)$

$$
\begin{array}{ccc}
0.2494+j 0.8748 & 0.0592+j 0.4985 & 0.0592+j 0.4462 \\
0.0592+j 0.4985 & 0.2494+j 0.8748 & 0.0592+j 0.4985 \\
0.0592+j 0.4462 & 0.0592+j 0.4985 & 0.2494+j 0.8748
\end{array}
$$

\section{References}

[1] International Electrotechnical Commission, 'IEC/TR 61000-3-13: Electromagnetic Compatibility (EMC) - Limits - Assessment of Emission Limits for the Connection of Unbalanced Installations to MV, HV and EHV Power Systems, Ed. 1,' (International Electrotechnical Commission, 2008).

[2] Neto, A. F. T., Cunha, G. P. L., Mendonca, M. V. B., and Filho, A. L. F.: 'A comparative evaluation of methods for analysis of propagation of unbalance in electric systems'. Proc. 6th Transmission and Distribution: Latin America Conference and Exposition, September 2012, pp. 1-8. 
[3] Chindris, M., Cziker, A., Miron, A., Balan, H., Iacob, A., and Sudria, A.: 'Propagation of unbalance in electric power systems'. Proc. 9th International Conference on Electrical Power Quality and Utilisation, Barcelona, Spain, October 2007, pp. 1-5.

[4] Kolagar, A. D., Hamedani, P., and Shoulaie, A.: 'The effects of transformer connection type on voltage and current unbalance propagation'. Proc. Power Electronics and Drive Systems Technology, Tehran, Iran, February, 2012, pp. 308-314.

[5] Liu, Z. and Milanovic, J.: 'Probabilistic estimation of voltage unbalance in mv distribution networks with unbalanced load', IEEE Transactions on Power Delivery, 2014, PP, (99), pp. 1-1.

[6] Woolley, N. C. and Milanovic, J. V.: 'Statistical estimation of the source and level of voltage unbalance in distribution networks', IEEE Transactions on Power Delivery, 2012, 27, (3), pp. 1450-1460.

[7] Seiphetlho, T. and Rens, A.: 'On the assessment of voltage unbalance'. Proc. 14th International Conference on Harmonics and Quality of Power, Bergamo, Italy, September 2010, pp. 1-6.

[8] Paranavithana, P., Perera, S., and Koch, R.: 'An improved methodology for determining MV to LV voltage unbalance transfer coefficient', Proc. 13th International Conference on Harmonics and Quality of Power, Wollongong, Australia, October 2008, pp. 1-6.

[9] Paranavithana, P. 'Contributions towards the development of the technical report IEC/TR 610003-13 on voltage unbalance emission allocation'. Ph.D. thesis, University of Wollongong, 2009.

[10] Renner, H.: 'Voltage unbalance emission assessment'. Proc. Electric Power Quality and Supply Reliability Conference, Kuressaare, Estonia, June 2010, pp. 43-48.

[11] Jayatunga, U., Perera, S., and Ciufo, P.: 'Voltage unbalance emission assessment in radial power systems', IEEE Transactions on Power Delivery, 27, (3), pp. 1653-1661.

[12] Jayatunga, U., Perera, S., Ciufo, P., and Agalgaonkar, A. P.: 'Voltage unbalance emission assessment in interconnected power systems'. IEEE Transactions on Power Delivery, 28, (4), pp. $2383-2393$.

[13] International Electrotechnical Commission, 'IEC/TR 61000-3-7: Electromagnetic Compatibility (EMC) - Limits - Assessment of Emission Limits for Fluctuating Loads in MV and HV Power Systems, Ed. 1' (International Electrotechnical Commission, 1996). 
[14] Paranavithana, P., Perera, S., and Koch, R.: 'Propagation of voltage unbalance from HV to MV power systems'. Proc 20th International Conference and Exhibition on Electricity Distribution Part 1, Prague, Czech Republic, June 2009, pp. 1-4.

[15] Paranavithana, P.: 'Propagation of voltage unbalance from HV to MV power systems'. Proc. 20th International Conference and Exhibition on Electricity Distribution - Part 2, Prague, Czech Republic, June 2009, pp. 1-2.

[16] Krause, P. C., Wasynczuk, O., and Scott, D. S.: 'Analysis of Electric Machinery and Drive Systems' (John Wiley and Sons, 2002, 2nd edn.)

[17] Glover, J. D. and Digby, G.: 'Preliminary Edition, Software Manual - Power System Analysis and Design' (PWS Publishing, 1994)

[18] Jayatunga, U., Perera, S., Ciufo, P., and Agalgaonkar, A. P.: 'Voltage unbalance emission assessment: Sources of contribution and their ranking'. Proc. Australasian Universities Power Engineering Conference (AUPEC), Hobart, Australia, September 2013, pp 1-8. 